\author{
S. Severi • M. Malavolti • N. Battistini • G. Bedogni
}

\title{
Some applications of indirect calorimetry to sports medicine
}

\begin{abstract}
Some applications of indirect calorimetry to sports medicine are discussed and exemplified by case reports. In particular, it is suggested that oxigen consumption can be employed to assess the effects of physical activity on fatfree tissues and that the respiratory quotient may offer some insights into the food habits of athletes.
\end{abstract}

Key words Sport • Exercise • Indirect calorimetry • Basal energy expenditure $\cdot$ Respiratory quotient

S. Severi • M. Malavolti • N. Battistini • G. Bedogni

Department of Biomedical Sciences

Faculty of Medicine and Surgery

University of Modena and Reggio Emilia, Modena, Italy

G. Bedogni ( $)$

Human Nutrition Chair, Department of Biomedical Sciences

Faculty of Medicine and Surgery

University of Modena and Reggio Emilia

Via Campi 287, I-41100 Modena, Italy

\section{Introduction}

Indirect calorimetry is the method of choice for measuring energy expenditure (EE) in human subjects. By measuring $\mathrm{O}_{2}$ consumption $\left(\mathrm{VO}_{2}\right), \mathrm{CO}_{2}$ production $\left(\mathrm{VCO}_{2}\right)$, and urinary excretion of nitrogen $\left(\mathrm{N}_{\mathrm{U}}\right)$, indirect calorimetry offers an estimate of basal (BEE), resting (REE) and activity (AEE) energy expenditure $[1,2]$.

It should be noted that while $\mathrm{VO}_{2}, \mathrm{VCO}_{2}$, and $\mathrm{N}_{\mathrm{U}}$ are measured, EE is estimated from these values on the basis of assumptions based mainly on studies performed in vitro [1]. Thus, EE is not a measurable entity and this explains why in selected research settings it is preferable to employ direct $\mathrm{O}_{2}$ measurements other than EE estimates [3]. However, following traditional use, we shall speak of EE measurement when referring to its estimation from $\mathrm{VO}_{2}, \mathrm{VCO}_{2}$, and $\mathrm{N}_{\mathrm{U}}$.

$\mathrm{BEE}$ is the energy expended in the postabsorptive state (at least $8 \mathrm{~h}$ after a meal) by an individual resting in a supine position, in the absence of physical and psychological stress, and at normal body and ambient temperature [2]. REE is the sum of BEE and the thermic effect of food (TEF) [2]. This latter is the energy expended for the absorption and utilization of nutrients and can be calculated from the difference between REE and BEE [4]. REE is measured under the same conditions as BEE, except that the individual is in the absorptive rather than postabsorptive state [2]. AEE can be measured by portable indirect calorimeters and offers an indication of the energy expended to perform physical activity [5].

The $\mathrm{VCO}_{2}: \mathrm{VO}_{2}$ ratio, better known as respiratory quotient (RQ), offers an indication of the energy substrate being consumed by an individual. Since RQ is very sensitive to changes in food intake, it can be better interpreted if (at least) a 7-day diary (7DD) of the food consumed by the subject undergoing the measurement is available. The 7DD does allow an accurate assessment of macronutrients compared with direct chemical analysis $[6,7]$. This paper focuses on the significance of BEE and RQ assessment in Sports Medicine. 


\section{Indirect calorimetry as a means for estimating the effects of physical activity on the most metabolically active tissues of the body}

All the cells of the body expend energy to perform their functions. However adipocytes store more energy than they actually consume, being responsible for only $5 \%$ of BEE in the adult man [8]. Thus, $95 \%$ of BEE is consumed by cells that make up fat-free tissues. Although this definition depends upon some approximations - most notably that the adipocyte is made up only of fat (Fig. 1) - it has nonetheless a great practical relevance. It suggests that $\mathrm{BEE}$ (or $\mathrm{VO}_{2}$ ) could be employed as an index of the (most) metabolically active tissues of the body [3]. However the fat-free mass (FFM) is a heterogeneous compartment, made of water, proteins, mineral, and glycogen (Fig. 1) and the use of BEE (or $\mathrm{VO}_{2}$ ) as an index of the metabolically active tissues of the body should always take this into account.

Despite these limitations, the estimate of fat-free tissues from $\mathrm{BEE}$ ( or $\mathrm{VO}_{2}$ ) is considered much more accurate than its estimate from more indirect measurements, such as weight, height, skinfolds, bioelectrical impedance... etc. [3].

It should be noted that the measurement of total body potassium (TBK) and intracellular water does add substantially to the evaluation of the metabolically active fraction of the body [3]. The cell is in fact made up mainly of water, and $98 \%$ of TBK is located inside it.

\section{Case report}

We shall discuss the utilization of BEE as an index of fatfree or metabolically active tissues by reporting the case of a 27-year-old basketball player enforced to rest by a lumbar hernia. Being slightly overweight [body mass index $(B M I)=25.0 \mathrm{~kg} / \mathrm{m}^{2}$, triceps skinfold $>75$ th NCHS/WHO percentile] he was referred to us at the beginning of the athletic season, to obtain a personalized dietary programme. His BEE was then $2,038 \mathrm{kcal} /$ day $[21 \mathrm{kcal} / \mathrm{kg}$ of body weight, (BW)]. Six months after the beginning of the athletic season, he had lost $4 \mathrm{~kg}$ but his BEE had increased in both absolute $(2,370 \mathrm{kcal} / \mathrm{day},+16 \%)$ and relative terms $(26 \mathrm{kcal} / \mathrm{kg} \mathrm{BW}$, $+23 \%$ ). Thus, as confirmed by skinfold measurements (data not shown), his weight loss had consisted primarily of fat tissues and his overall metabolic efficiency had improved, also through the expansion of fat-free tissues. The occurrence of such an expansion can be inferred from the large percentage increase of both $\mathrm{BEE}$ and $\mathrm{BEE} / \mathrm{BW}$. While it is well known that a few days of bed rest may decrease BEE without detectable changes in fat-free tissues and that this may be reversed by just a few days of exercise, increases of this entity cannot be explained without hypothesizing an expansion of FFM. [It goes without saying that in order to identify a change in the quantity (or quality) of fat-free tissues, one needs to know both the intra-individual (biological) and intra-calorimeter (instrumental) variability associated with the use of indirect calorimetry [3]]. At about 7

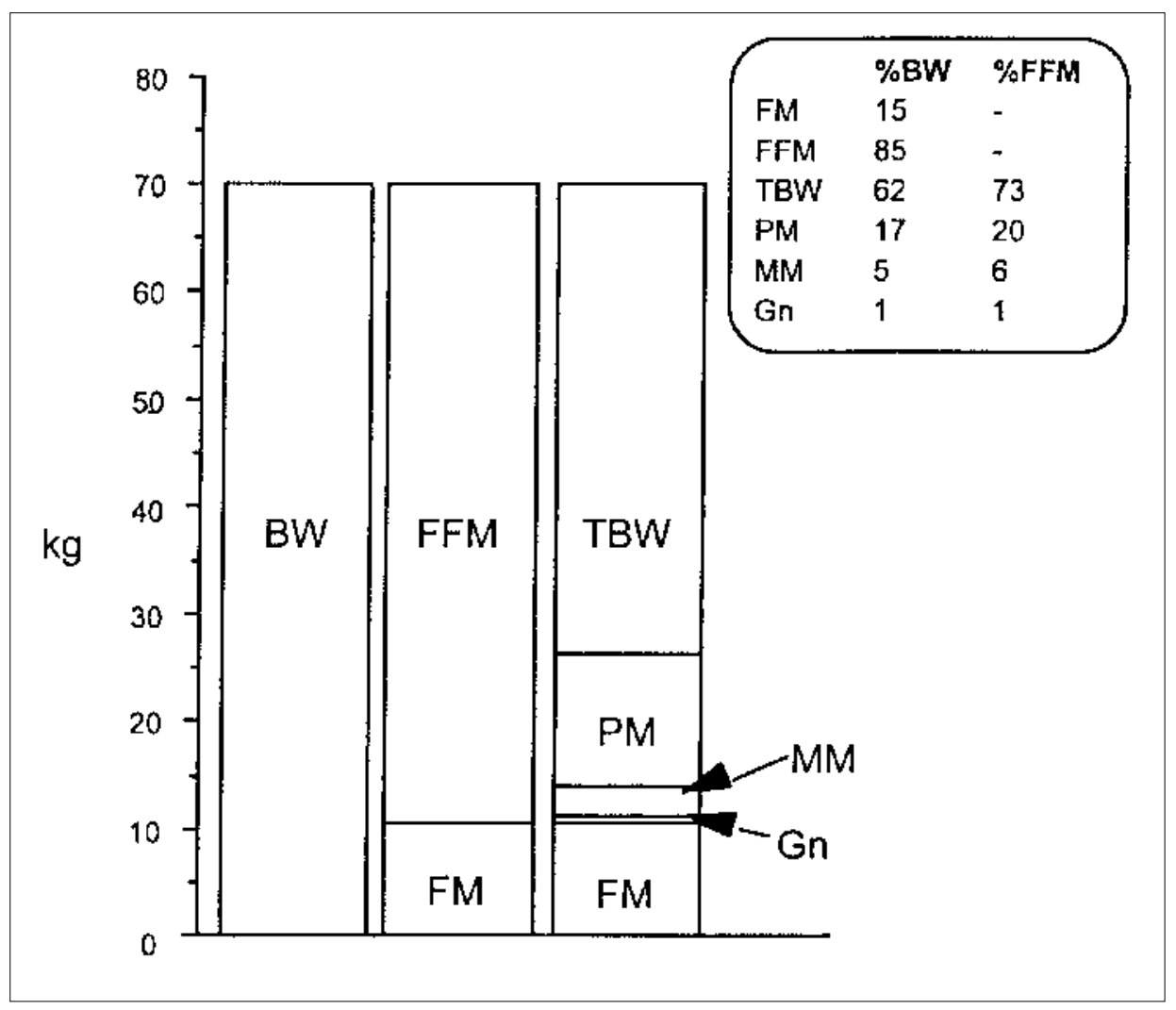

Fig. 1 Body composition in the reference man [1]. $B W$, Body weight; $F F M$, fat-free mass; $F M$, fat mass; $T B W$, total body water; $P M$, protein mass; $M M$, mineral mass; $G n$, glycogen 
months after the beginning of the athletic season, our athlete was obliged to rest for 1 month due to a lumbar hernia. At a pre-programmed measurement of BEE 1 month later, his BEE had dropped to $2,094 \mathrm{kcal} /$ day $(23 \mathrm{kcal} / \mathrm{kg}$ ). The most likely explanation for this decrease in BEE is clearly his enforced rest with complete suspension of training sessions.

\section{Indirect calorimetry as a means for identifying the nutrients consumed by an athlete}

RQ offers an indication of the energy substrates consumed by an individual. However, since indirect calorimetry reflects short-term changes in nutritional status, the only way of declaring a RQ value as "typical" for a given individual is to measure it more than once (this may however not be feasible for values within the normal range). The availability of (at least) a 7DD is of considerable aid for interpreting deviations of RQ from its normal values.

\section{Case report}

A 30-year-old female volleyball player was sent to us at the beginning of the athletic season for dietetic advice. The woman weighed $66 \mathrm{~kg}$ and had a BMI of $19.7 \mathrm{~kg} / \mathrm{m}^{2}$. Her BEE was $1,147 \mathrm{kcal} /$ day (17 kcal/kg) and her RQ was 1.09 . After careful checking of the calorimeter, virtually identical values of RQ were measured on two consecutive occasions during the same week. After exclusion of a measurement error, a value of $\mathrm{RQ}>1.000$ does theoretically suggest the presence of lipogenesis [2]. Although the 7DD of our athlete clearly showed an excessive intake of carbohydrates, it is well known that even carbohydrate meals induce lipogenesis to a minimal extent [2]. Thus, we searched for alternative explanations. A new dietary and drug history was obtained and the woman admitted of having consumed "traditional herbal remedies" for years including an ill-defined "fatburner". (She had denied the use of such substances during the first interview. In addition to the use of dietary supplements, it is our policy to ask about the use of herbal products and hormones, altough some subjects tend to deny their use and may admit it only when they have reached a sufficient degree of confidence with the nutritionist). Hypothesizing that these "herbal remedies" could be at least in part responsible for her deranged metabolism, we suggested that she stop their use. We also tried to make her diet more balanced, since fats were underrepresented with respect to carbohydrates and proteins. Six months after the first measurement (corresponding to 6 months of training), her BEE had increased to $1,400 \mathrm{kcal} /$ day with virtually no modification of BW, and while her RQ was still high (0.9), it could be considered within normal limits.

\section{Conclusion}

We show two very basic applications of indirect calorimetry that may be of interest to sports physiologists and physicians. We have pointed out the importance of measuring the food intake of the athlete in order to achieve a better interpretation of his/her metabolic data. An assessment of body composition should also always be added to obtain data that may be used to improve the performance of the athlete (Fig. 2).
Fig. 2 An operational definition of nutritional status [1]

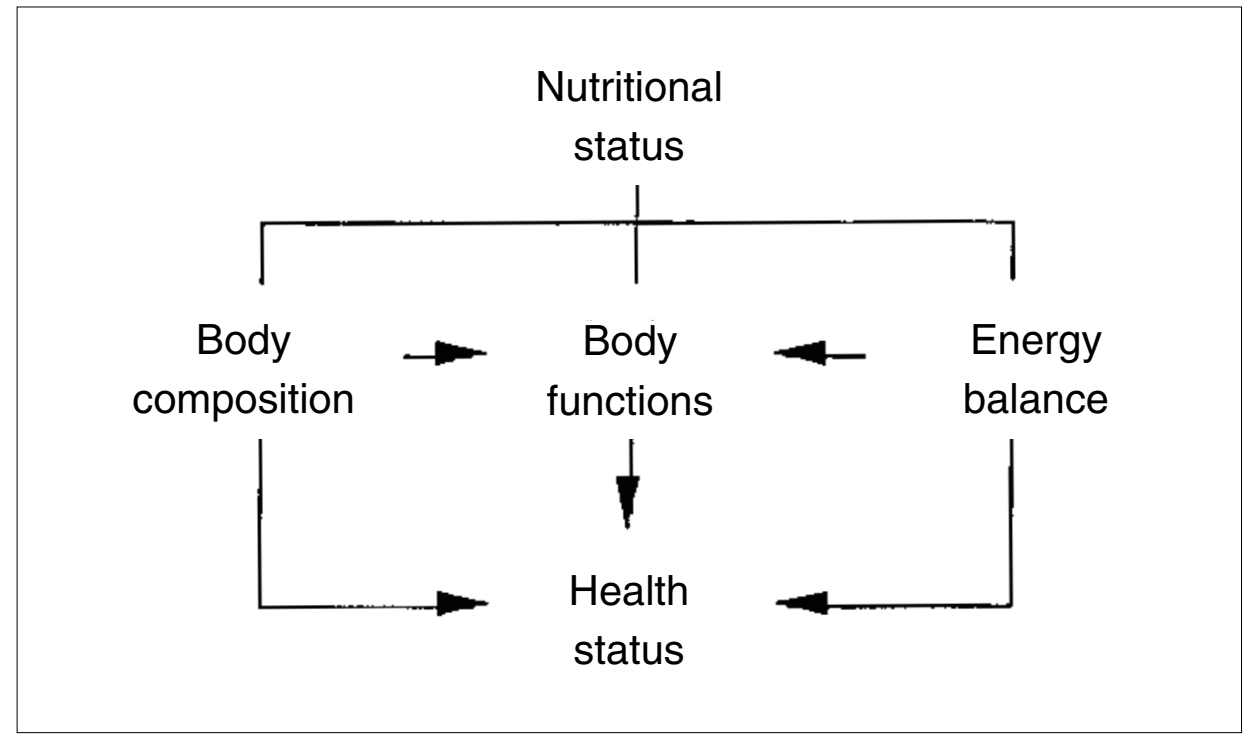




\section{References}

1. Ferranini E (1998) The theoretical bases of indirect calorimetry: a review. Metabolism 37:287-301

2. Burzstein S, Elwyn DH, Askanazi J, Kinney MJ (1989) Energy metabolism, indirect calorimetry and nutrition. Williams and Wilkins, Baltimore

3. Bedogni G, Battistini N, Borghi A (1999) Principi di valutazione dello stato nutrizionale. EDRA, Milano

4. James WPT (1992) From SDA to DIT to TEF. In: Kinney MJ, Tucker HN (eds) Energy metabolism: tissue determinants and cellular corollaries. Raven, New York, pp 163-183

5. Montoye HJ, Kemper HCG, Saris WHM, Washburn RA
(1996) Measuring physical activity and energy expenditure. Human kinetics, Champaign, Illinois

6. Battistini N, Caselli D, Bedogni G, Gatti G (1992) Food intake in university students and its impact on nutritional status. Nutr Res 12:223-233

7. Bedogni G, Bernini, Carri E, Gatti G, Severi S, Poli M, Ferrari F et al (1999) Comparison of food composition tables and direct chemical analysis for the assessment of food intake in a military community. Int J Food Sci Nutr 50:73-79

8. Elia M. (1992) Organ and tissue contribution to metabolic rate. In: Kinney JM, Tucker HN (eds) Energy metabolism: tissue determinants and cellular corollaries. Raven, New York, pp 61-79 